\section{Sobre encefalitis herpética}

Herpes encephalitis

\section{Sr. Editor:}

Completamente de acuerdo con lo expresado por Walter Ledermann en su carta publicada en la Revista Chilena de Infectología 2012, 29 (5): 578 respecto al desafortunado título del artículo "Encefalitis herpética neonatal: valor de la clínica versus biología molecular" publicado en la misma revista en el volumen 290 (4):4647. Muy por el contrario al enfrentamiento entre ellas, el aporte de cada una sumando sus capacidades facilita el certero y oportuno diagnóstico. Ejemplo de esto es el mismo artículo antes mencionado, donde la técnica no se opone a la clínica. De acuerdo a lo mostrado en la figura 1, la clara elevación de la curva de fluorescencia-incluso en la primera muestra de líquido cefalorraquídeo- apoya el diagnóstico de VHS. El valor de corte utilizado para interpretar el resultado como negativo $(\mathrm{Ct}<32)$ es un valor arbitrario que varía según el kit utilizado, no siempre debidamente validado. En nuestra experiencia de años en el diagnóstico virológico en general, y en la detección genómica viral por RPC en particular, hemos comprobado en varias ocasiones que curvas como las observadas corresponden realmente a resultados positivos, a pesar del $\mathrm{Ct}$ mayor al referido como valor de corte por el fabricante. Así, siempre es útil analizar e interpretar un resultado en conjunto con la clínica del paciente, donde las técnicas de laboratorio son un aporte, sin olvidar que un diagnóstico no debe establecerse basado sólo en el resultado de un examen.

Finalmente, como la adecuada interpretación de un examen de laboratorio, en este caso la RPC, es crucial en el aporte que realizan las técnicas de laboratorio, parece aconsejable que "la pizca de intuición que acompaña a la clínica”, según expresan los autores en su carta respuesta, también sea acompañada por la experiencia de quienes trabajamos en el laboratorio y así el trabajo conjunto con el médico clínico conducirán - hacia y no contra - el diagnóstico oportuno que favorecerá al paciente.

Le saluda atentamente

Vivian Luchsinger Programa de Virología Instituto de Ciencias Biomédicas Facultad de Medicina, Universidad de Chile. 